\title{
Orchestrating the Participation of Women Organisations in the UNFCCC Led Climate Finance Decision Making
}

\author{
Svetlana Frenova
}

Citation: Frenova, S. Orchestrating the Participation of Women Organisations in the UNFCCC Led Climate Finance Decision Making. Climate 2021, 9, 135. https: / / doi.org/10.3390/cli9090135

Academic Editor: Thomas Beery

Received: 13 July 2021

Accepted: 25 August 2021

Published: 27 August 2021

Publisher's Note: MDPI stays neutral with regard to jurisdictional claims in published maps and institutional affiliations.

Copyright: (C) 2021 by the author. Licensee MDPI, Basel, Switzerland. This article is an open access article distributed under the terms and conditions of the Creative Commons Attribution (CC BY) license (https:// creativecommons.org/licenses/by/ $4.0 /)$.
Department of Governance and Technology for Sustainability, The University of Twente, 7522 NB Enschede, The Netherlands; s.frenova@utwente.nl

\begin{abstract}
The study applies orchestration as a conceptual framework to provide early evidence on the engagement of women organisations in UNFCCC-led climate finance governance and reflect on the quality of their mobilisation. Women organisations are one of the non-state stakeholders, whose role is acknowledged in the UNFCCC Decision 3/CP.25 for improving gender-responsiveness of climate finance. Within the UNFCCC, orchestration is used as a governance approach to enhance the mobilisation of non-state actors for facilitating the implementation of policy goals. The study utilises mixed methods including document review and interviews with key informants. The findings of the study indicate that the quality of orchestration has been low, i.e., the engagement of women organisations in the UNFCCC-led climate finance decision making has, so far, been limited. This is due to the lack of policy convergence on the purposes of orchestration, as well as the newness, and complexity of the issues at the intersection of climate finance and gender. While the concept of orchestration is intended to enhance decision making practices, the study suggests that in the case of the engagement of women organisations in the UNFCCC-led climate finance governance, orchestration is used only for symbolic purposes. To make the engagement of women organisations more meaningful, there is a need to diversify the existing orchestration practices and improve consistency in policy framing.
\end{abstract}

Keywords: UNFCCC; climate policy; climate finance; stakeholder engagement; gender equality

\section{Introduction}

The increased participation of non-state actors as stakeholders in climate change policymaking has been historically championed within the United Nations Framework Convention on Climate Change (UNFCCC) [1]. Non-state actor participation is considered to play an increasingly important role in the post-Paris Agreement era [2]. It is argued that such stakeholders can influence high-level policy dialogue while bringing two particular benefits. Firstly, non-state actors provide direct access to local information and knowledge which is generally unavailable to international organisations and nation states [3-5]. Secondly, the involvement of non-state actors increases the range of societal groups contributing to policy formulation as a more inclusive process.

Women organisations are an example of non-state actors that can be of interest to intergovernmental organisations, such as the UNFCCC, to engage with since women organisations are a unique type of stakeholder whose participation is linked with the integration of a gender perspective in global public policy [5]; as well as promotion of the rights of women and gender equality [6,7]. Women organisations are defined as such institutions and arrangements that have three essential elements: identity with women as a group; language that is explicitly gendered; ideas that are expressed as women representing women [7].

Women organisations can play an important role in fostering the implementation of inclusive policies [8], while creating the space for grassroots organisations and empowering local and national civil society [8-10]. One approach for making the engagement of 
non-state actors more meaningful is for the UNFCCC to coordinate or orchestrate their participation. Orchestration is a mode of governance which uses indirect and soft methods of steering through partner organisations or intermediaries that possess experience and contacts that the UNFCCC does not have and so it helps the UNFCCC more readily to reach its objectives. Research shows that the UNFCCC is acknowledged as the central orchestrator of non-state actors within global climate governance [11,12]. Indeed, the UNFCCC's method of operation can be seen as the UNFCCC acting as an orchestrator and mobilising intermediaries (like constituencies) through ideational support, and engaging with non-state actors with relevant expertise (target actors) in the attempt to facilitate the implementation of the policy goals by bringing their additional knowledge and capacities into the policy formulation process [13].

In respect of women organisations, the UNFCCC recognises women organisations as important non-state actors in relation to climate finance which is a mechanism for the implementation of the UNFCCC's policies. A clear statement of the UNFCCC recognition of the role of women organisations comes in UNFCCC Decision 3/CP.25 [14] in which the role of women grassroots organisations and women groups is acknowledged as important for improving gender-responsiveness of climate finance.

This article explores the existing orchestration practices used by the UNFCCC in relation to women organisations (as non-state actors) and analyses the quality of their orchestration for facilitating the implementation of UNFCCC policy objectives, e.g., improving participation of women organisations and achieving gender-responsiveness of climate finance. To do this I use the concept of orchestration which is described in the next section. After which, the article sets out the problem statement and continues with the description of the methodology. Then, the article presents findings that describe the existing orchestration approaches and analyses the quality of these approaches. The article concludes with a discussion on how to interpret the findings and makes some research and policy recommendations for the mobilisation of women organisations within UNFCCC-led climate finance governance.

\section{Orchestration: A Concept for Understanding the Participation of Non-State Actors in Multi-Layered Governance Frameworks}

The orchestration concept has been widely recognised within political science scholarship as a tool to study participation and interactions between state and non-state actors within multi-layered governance frameworks [13], and more specifically within the UNFCCC $[11-13,15,16]$. Orchestration is seen as arrangements that do not rely on legal enforcement but on voluntary coordination among state and non-state actors to improve the achievement of policy goals $[17,18]$.

The key feature of the orchestration concept is a model which describes the various roles in the process of orchestrating, i.e., Orchestrator-Intermediary-Target [13]. Within this model, orchestrators, in the pursuit of policy goals, mobilise intermediaries (including the private sector, civil society, transnational networks) to reach out to targeted actors (for example, grassroot women organisations). Intermediaries are considered a necessary element in orchestration because they can possess local information, technical expertise, enforcement capacity, material resources, legitimacy, and direct access to targets, which the orchestrator lacks [4]. In addition, meta-intermediaries (i.e., institutional mechanisms) could be utilised to provide additional steering of intermediaries on certain issues [12].

Orchestration is expected to improve the implementation of policy goals by engaging with various types of expertise and improving the capabilities of the orchestrator in areas where it lacks experience, contacts, or authority [4]. Abbott et al. [13] have produced a typology of orchestration approaches:

- Convening: providing opportunities to deliver policy messages through contact with influential actors, through participation in the meetings and/or a variety of mechanisms (e.g., side events);

- Agenda setting: providing guidance on policy solutions; 
- Assistance: providing material (e.g., travel funds) and capacity support;

- Endorsement: acknowledging and empowering intermediaries as competent and legitimate actors;

- Coordination: ensuring the alignment of the orchestrator's activities with those of intermediaries.

The orchestration concept relies on a functionalist approach implying that non-state actors can contribute to filling governance deficits in knowledge, information and implementation [9]. Thus, the quality of orchestration could have an impact on the achievement of policy goals. In previous studies, the quality of orchestration has been linked with:

- Meaningful recognition of intermediaries of orchestration [19];

- Explicit policy mandates that specify what the participation is intended to achieve [19];

- Availability of resources and strategies to overcome barriers to participation [20,21].

While the concept of orchestration suggests that it is intended to enhance governance practices, in reality it may be used for symbolic purposes without having a significant impact on policies.

\section{UNFCCC-Led Orchestration of Women Organisations towards Meaningful Participation}

There are two intermediaries within the UNFCCC system which can play an important part in enabling women organisations' meaningful participation in climate finance: The Standing Committee on Finance (SCF) and The Women and Gender Constituency (WGC).

The SCF is a constituted body with limited membership (consisting of governmental actors drawn from signatories to the UNFCCC) that provides technical support to the UNFCCC on climate finance issues, including the mobilisation, measurement, reporting, and verification of funds. Constituted bodies are institutional arrangements with limited membership that provide technical advice to the Convention, the Kyoto Protocol and the Paris Agreement. The Women and Gender Constituency (WGC) is one of nine official observer groups of the UNFCCC. The WGC's goal is to "formalise the voice of the women's and gender civil society organisations".

The manner in which the UNFCCC can utilise these two intermediaries to engage with women organisations is to use the mandate of the Standing Committee on Finance (SCF) to engage and steer non-governmental actors, including the WGC, which in turn directly coordinates with women organisations (Figure 1). In other words, the UNFCCC is the orchestrator of a meta-intermediary (SCF) which orchestrates an intermediary (WGC) to engage with the target (women organisations).
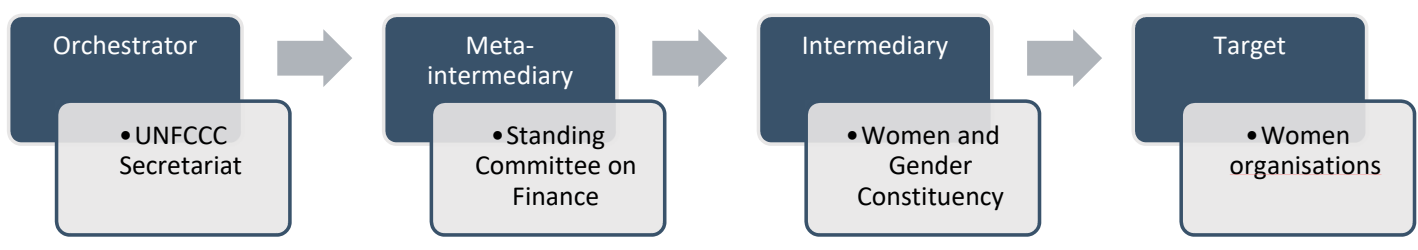

Figure 1. Orchestrating the engagement of women organisations in the UNFCCC led climate finance decision making (developed by the author).

For both the UNFCCC and women organisations, orchestration efforts to mobilise women organisations to contribute to climate finance decisions should be of sufficient quality to allow both actors to reach their policy objectives. However, without adequate policy framing of orchestration and understanding of the existing barriers to the meaningful participation of women organisations, the outcome could be that women organisations fail to reach their full potential to influence the outcomes of climate policy which would also be detrimental to the UNFCCC. It is therefore timely to assess the existing orchestration approaches to support engagement of women organisations in the UNFCCC-led climate 
finance decision-making and to evaluate the quality of orchestration efforts to involve women organisations. To make this assessment I answer the following two questions:

1 What are the existing orchestration approaches to support the engagement of women organisations in UNFCCC-led climate finance decision-making?

2 What is the quality of orchestration efforts to involve women organisations?

The main objectives of the study are firstly to provide early evidence on the existing orchestration approaches to engage women organisations in UNFCCC-led climate finance governance and, secondly, to reflect on the quality of the orchestration efforts which enable the UNFCCC to achieve its objectives and that women organisations, as non-state actors, are able to participate meaningfully.

A third objective is, where necessary, to develop policy recommendations for enhancing the orchestration of women organisations in UNFCCC-led climate finance decision-making.

In addition, the study contributes to theory through an innovative look at multilevel governance, using the concept of orchestration to explore processes at the intersection of climate finance and gender equality.

\section{Methods}

Based on the description in the previous section of the UNFCCC governance system in respect to climate finance and the two questions posed, the objectives of the methodology are to:

- Provide evidence of orchestration by mapping and describing the orchestration approaches; and

- Reflect on the quality of the orchestration.

The study utilises mixed methods, i.e., document review and interviews with key informants. The documents reviewed were:

- 214 substantive SCF documents including annual reports, background papers, guidance to financial mechanisms, and records on the outcomes of the meetings. The documents have been accessed at https:// unfccc.int/scf/scf-meetings-and-documents (accessed on 30 March 2021);

- 31 official submissions of the WGC and their members tracked through the UNFCCC's website: https:/ / unfccc.int/ process-and-meetings / parties-non-party-stakeholders/nonparty-stakeholders/submissions/submissions-from-non-party-stakeholders (before 2018) (accessed on 30 March 2021); https:/ / www4.unfccc.int/sites/submissionsstaging/Pages/ Home.aspx (after 2018) (accessed on 30 March 2021);

- 120 records of WGC's interventions made at the UNFCCC's meetings, which are available at the WGC's website: https:/ / womengenderclimate.org/resource/ (accessed on 30 March 2021).

These documents were analysed using ATLAS Software. The texts of SCF documents were scanned using the search terms "women", "female" or "gender". The fragments of texts associated with the use of these terms were scrutinised to identify references to organisations and institutional actors who are described using the above-mentioned gendered terms. The texts of the WGC's submissions were analysed using the search term "finance" to identify specific narratives related to the role of women organisations in climate finance.

Semi-structured interviews were conducted with four experts. These experts were selected to cover each of the four groups of actors in the orchestration process as described in Figure 1:

- Interviewee A (representative of the UNFCCC Secretariat: the Orchestrator);

- Interviewee B (SCF expert: the Meta-intermediary);

- Interviewee C (WGC focal point to SCF: the Intermediary);

- Interviewee D (WGC member: the Target). 
In line with the University's ethical policy, the interviewees are not identified by name but by a code. Each interview lasted approximately one hour, and each was recorded with the interviewees' consent which is in keeping with the university's ethical guidelines.

The questionnaire covered the following topics:

(1) the existing UNFCCC's participatory processes and UNFCCC's management of participation specifically in relation to women organisations, including challenges and barriers to the participation of women organisations;

(2) approaches utilised by women organisations for influencing policy outcomes; and the perception of limitations and opportunities associated with these approaches;

(3) awareness on the influence of women organisations on climate finance policy making, including specific language being integrated and/or enhanced; norms or targets being adopted; commitments increased, etc.

The data generated was used to answer the two research questions using different frameworks. The first question is answered using the framework proposed by Abbott et al. (2015), described above. An analysis of the UNFCCC's guidelines and documents on participation together with interviews with experts are used to describe the specific approaches that exist within the orchestration model (as per Figure 1).

The analysis on the quality of orchestration (the second question) is based on document review and expert interviews using semi-structured questionnaires. The following criteria to assess the orchestration quality were used:

- The extent of the engagement of the WGC (intermediary) in the SCF's meetings, which is conducted through the review of the list of participants.

- The extent of the mobilisation of women organisations (the targets) by the WGC, based on an analysis of its membership.

- Consistency across the policy framings, which are used by the orchestrator and intermediaries, in relation to the definition of 'women organisations' and the purposes specified for mobilising women organisations (assessed through document review via ATLAS Software).

- Presence of challenges and barriers to the participation of women organisations based on experts' interviews.

\section{Results}

\subsection{Existing Orchestration Approaches}

In this section, I provide an answer to the first research question by describing the existing approaches to orchestrate women organisations' engagement in climate finance decision-making under the UNFCCC. Here I use the typology as identified by Abbot et al. [13]: convening, agenda-setting, assistance and endorsement. The summary of the analysis is presented in Figure 2.

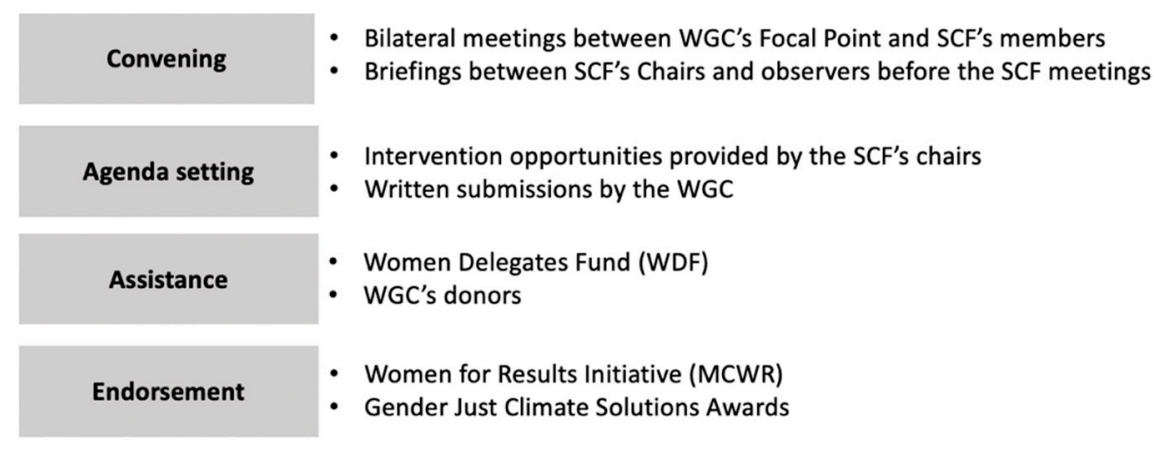

Figure 2. Existing orchestration approaches to support the engagement of women organisations in in climate finance decision-making under the UNFCCC (developed by the author).

Convening: Constituencies, which include women organisations, are invited to hold bilateral meetings with SCF members to share position papers and submissions, and advo- 
cate for policy perspectives. The constituencies engage with constituted bodies through the constituency's focal point, who convey joint constituency statements. In addition, nonparty stakeholders can advocate through the organisation of press conferences, side events, and exhibits. Another opportunity to convey messages is at workshops and meetings of the constituted bodies, which are seen as platforms for retrieving experts' advice and inputs.

Interviewee A explained that, in 2018, the SCF opened up participation in its meetings to a broader range of stakeholders. The SCF was one of the first constituted bodies within the UNFCCC offering constituencies this engagement modality. If the time allows, observers from the constituencies are given the floor to provide inputs on agenda items. Before 2018, if constituencies came to the meetings, their participation was only as observers, although they could discuss policy matters informally before or after meetings and during breaks. In 2018, a more formal orchestration process was instituted and included regular briefings with observers before the SCF meetings, which have been attended by the WGC Focal Point. The WGC's Focal Point is allowed to attend the break-out group discussions, which focus on technical matters.

The WGC has been offered an opportunity to hold informal dialogues with SCF members, for instance during coffee breaks. Interviewee $C$ stated that the WGC has been mostly delivering policy messages through these informal bilateral meetings.

Agenda setting: Constituencies can contribute to agenda-setting by responding to the calls for information, developing position papers, and making formal submissions. In addition, there is a possibility to make interventions during the plenaries and meetings of constituted bodies. Intervention opportunities are provided by the chairs of the respective bodies. The WGC has been providing written submissions (see under methodology for the references), for example on climate finance, as a key means for the implementation of gender-responsive climate actions. The opportunities to submit inputs are provided by co-chairs of the SCF and are available on the SCF's website.

Assistance: There have been initiatives to provide travel funds to support women's engagement in national delegations and the participation of grassroots local and indigenous peoples' communities in the UNFCCC. For instance, the Women Delegates Fund (WDF) was established in 2009 through the support of several donors (including the governments of Australia, Canada, France, Iceland, the Netherlands, Scotland, Sweden, and Switzerland) to support the participation of women from grassroots, local and indigenous communities. The WDF falls under the jurisdiction of the WGC, which, at the time of writing, is administered by the Women's Environment and Development Organisation (WEDO) as the acting administrator of the WGC. The WDF covers travelling costs only for delegates who are part of the official government delegation and are nominated by the UNFCCC Focal Points. In some cases, the WDF nominates candidates as UNFCCC Focal Points. Since 2017, WDF has supported over 63 trips by female experts, however, it is not evident how many of these women represented women organisations.

Financial assistance for participation in the SCF meetings is somewhat limited. According to Interviewee C, the WGC's donors see little value in prioritising participation by women organisations in the SCF's deliberations, which has led to low prioritisation of travel for attending the meetings, resulting in mostly virtual participation by the WGC in the SCF's events.

Endorsement: Some initiatives acknowledge the key role of women organisations in addressing broader climate change. For instance:

- UNFCCC's Momentum for Change: Women for Results Initiative (MCWR) (launched in 2012) showcases women-led initiatives as well as initiatives implemented by organisations with gender equality mandates that support climate action.

- Gender Just Climate Solutions Awards, organised by the WGC as side events held during the UNFCCC's meetings, to recognise the activities of women and women organisations in the implementation of transformative climate change policies and climate finance solutions. 


\subsection{The Quality of the Orchestration}

In this section, I describe the quality of orchestration using four indicators: (1) the extent of mobilisation of women organisations (targets) by the WGC (the intermediary); (2) the extent of the engagement between the WGC and the SCF (intermediary and metaintermediary); (3) the presence of barriers and challenges to the participation of women organisations; (4) consistency across the policy framings that are used by the orchestrator and intermediaries on how women organisations and the purposes of orchestration are defined by the UNFCCC.

\subsubsection{Mobilisation of Women Organisations by the WGC}

The WGC was established in 2009, and according to the website consists of 33 women's and environmental civil society organisations (Figure 3). Within these broader categories of organisations, the WGC members identify themselves as national, international, and regional NGOs, grassroots organisations, and networks. The WGC mobilises women organisations through a range of mechanisms. For example, organisations which are accredited as an observer organisation to the UNFCCC and work in alignment with the WGC goals and priorities can become members of the WGC. In addition, the WGC mobilises a broader range of organisation, who are not accredited to the UNFCCC through the WGC Advocacy List and the Women's Caucus. The WGC Advocacy List includes about 500 representatives of civil society who are engaged in developing climate policy positions and are contacted for information and sharing key advocacy positions. The Women's Caucus is a mailing list for all types of stakeholders interested in the WGC's work for sharing information and collective advocacy.

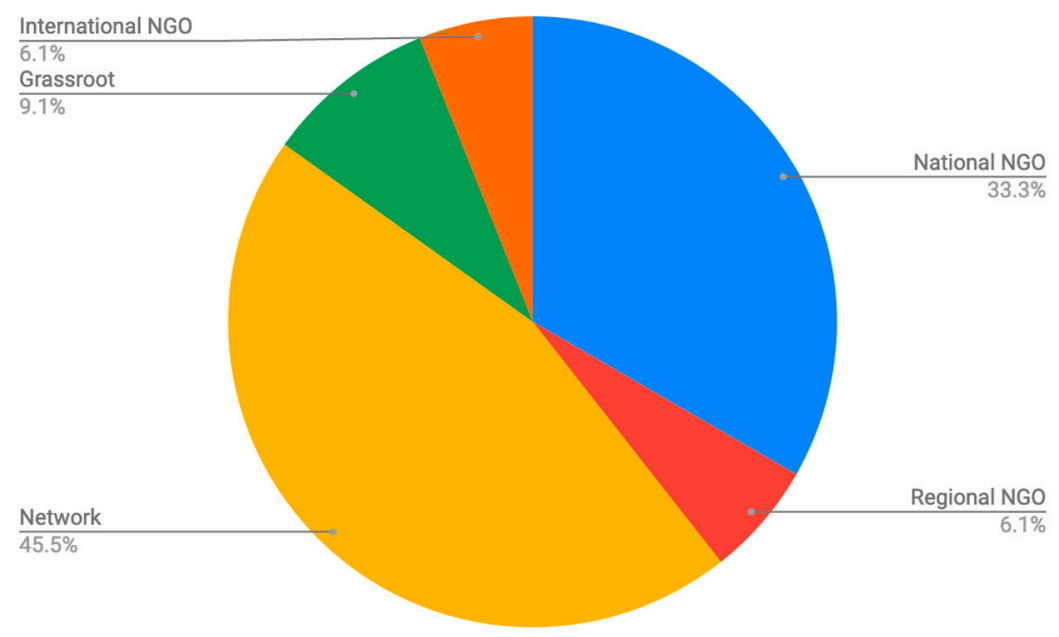

Figure 3. The composition of WGC (based on https:/ / womengenderclimate.org/member/, accessed on 30 March 2021).

According to the interviewee representing the WGC, expanding membership is not an ambition or an indication of effective mobilisation. Enhancing the representation of women organisations at UNFCCC meetings, or building knowledge of these organisations on the UNFCCC's decision-making, are not seen as an appropriate orchestration approach. Interviewee C stated: "It is not critical for local knowledge to be at the negotiations but it is critical to have an organising structure to mobilise and share knowledge between negotiations ... so the strategies can be built to connect international policies with locallevel experiences".

\subsubsection{Engagement between the SCF and WGC}

Since its establishment in 2012, the SCF has organised 23 meetings (as of March 2021, https:/ / unfccc.int/scf/scf-meetings-and-documents, accessed on 30 March 2021) Based on the analysis of the list of participants, the WGC participated in three SCF meetings. The 
participatory evidence correlates well with the information provided during the experts' interviews. According to the four interviewees (A, B, C, and D), the track record of WGC participation in meetings on climate finance issues under the UNFCCC is limited. The interviewees unanimously agreed that neither the SCF has been able to mobilise the WGC substantively nor has the WGC, so far, been able to make much impact on climate finance.

\subsubsection{Orchestration Challenges}

The interviewees, in attempting to explain the existing participatory challenges for women organisations, identified a number of issues which I group into three categories:

- Challenges that are related to general UNFCCC practices and rules, which define the constrained roles of civil society actors. These types of challenges are well captured in the literature and are inherent in the political setup of the UNFCCC decision-making processes [10,22].

- Challenges that are related to limitations on how the participation, at the intersection of climate finance and gender equality, is organised by the SCF and is taking place.

- Challenges that are related to specific WGC capacity issues to mobilise and influence climate finance decision-making.

Given the purpose of the study, I further reflect on orchestration challenges that are not generic, but specific to climate finance decision-making. For example, the limited opportunities for engaging in agenda-setting are linked with the political setup of the UNFCCC and its constituted bodies. According to the interviewees, meeting agendas are set in line with the Conference of the Parties' (COP) decisions and cannot be adjusted even by SCF members. However, Interviewee A noted that there are other opportunities to contribute indirectly to setting agendas, for instance through the provision of substantive outputs within the development of flagship reports, such as the biannual assessment of climate finance. These opportunities have not yet been fully utilised by the WGC.

Interviewees A, C, and D report that opportunities for enhancing non-state actors' roles (and more specifically Civil Society Organisations (CSOs)) lie with better awareness and recognition of their instrumental roles. In the opinion of the interviewees, there is a need to convey and demonstrate the utility of CSOs' participation in strengthening policy outcomes. There is anecdotal evidence that in some cases the instrumental value of CSOs is acknowledged. According to the interviewees, some Parties (i.e. Parties are countries which are signatories to UNFCCC) value CSOs' participation, because CSOs frequently share points that help Parties to prepare texts and talking points which help create stronger positions in negotiations about climate finance.

In terms of the management of participation at the SCF, interviewee $\mathrm{C}$ noted that following the decision-making processes at the SCF has been challenging. Transparency is limited in respect of how the policy documents are drafted and finalised. In theory, the WGCs' assigned focal points could work (between meetings) on untangling the logic of the decision-making process, but the capacities of the WGCs are limited for following up on each decision.

In addition, the interviewees agreed that the knowledge on the intersection of gender equality and climate finance is new and limited. As per interviewees A and C, it appears that for SCF members, the newness of gender equality as a topic results in limited integration and attention to these issues within the SCF's agendas, as well as hampering the mobilisation of women organisations. The SCF experts are knowledgeable about climate finance but have a low understanding of gender equality issues. On the other hand, all four interviewees perceive women organisations' technical knowledge of climate finance as limited. Interviewee $C$ noted that the content of the issues discussed at the SCF is extremely difficult to grasp and comprehend particularly for anyone without an understanding of finance.

Generally, all four interviewees are in agreement about the lack of capacity of the WGC to deliver systemic contributions to climate finance decision-making. These capacities are related to nascent organisational structure and limited availability of resources. 
In interviewee C's opinion, the WGC does not appear to have specific mandates related to climate finance. The funding that has been raised to support the work of the WGC has been geared to mainstream gender issues in policy texts. It is the interviewee's opinion that this is not necessarily an indication of a lack of attention to these issues, but rather one of a nascent level of organising and low level of resources. The perception of donors on how WGC's activities need to be prioritised does not have an insignificant impact on the WGC's participation in SCF meetings. Interviewee C noted that the WGC has had difficulties with convincing donors about the importance of travel for attending SCF meetings, which has led to mostly virtual participation in SCF events. As a consequence, the opportunities for informal meetings are not possible, resulting in lost possibilities for influencing policies and outcomes.

\subsubsection{Consistency of Policy Framings}

The study analysed the consistency of the policy framings that are used by the Orchestrator, Meta-intermediary and Intermediary in relation to the definition of 'women organisations' and the purposes of their mobilisation. The findings of the analysis are presented below.

The Orchestrator framing: The earlier analysis of the UNFCCC documents (presented in Section 2) argued that the participation of women organisations is considered as key for ensuring that climate finance is gender-responsive. The UNFCCC has clearly indicated, as shown by Decision 3/CP.25, that it expects women groups, grassroots women organisations, and national gender institutions to play an important role in ensuring the integration of gender issues in climate policies, plans, and strategies. In addition, grassroots women organisations are noted as recipients of climate finance. In line with this framing, the purpose of orchestrating women organisations could be presented as improving access to and ensuring the gender responsiveness of climate finance.

The Meta-intermediary framing: The analysis of the SCF documents revealed that the SCF appears to have gender mandates, which include inter alia reporting on progress towards integrating a gender perspective into the SCF processes and providing capacitybuilding to chairs and members on how to integrate gender considerations [23]. However, within these documents, there is no recognition of the role of women organisations in the implementation of these mandates. On the other hand, the guidance provided by the SCF to the UNFCCC Financial Instruments states that the participation of "women-led organisations" is linked with the development of inclusive strategies and strengthening gender-related actions of climate finance [24]. In addition, the role of women and gender constituency is noted (in the analysed SCF policy texts) in relation to facilitating the achievement of gender balance in the UNFCCC process and gender-sensitive climate policy [25]. In line with this framing, the purpose of the orchestration via the WGC may be seen as increasing both the participation of women in the policy process and gender sensitivity of climate policies.

The Intermediary's framing: Based on the analysis of women organisations' submissions to the UNFCCC, women organisations are interested in and aim to contribute to the following aspects of climate finance:

- Gender responsiveness: One of the key claims of women organisations is that $100 \%$ of climate finance needs to be gender-responsive.

- Equity: Women organisations claim that "climate finance is key to achieving just and equitable solutions to the climate crisis". In addition, women organisations advocate for better integration of gender equality considerations in climate finance policies, procedures, and approaches.

- Accessibility: Women organisations convey that access to climate finance needs to be ensured for the world's farmers and direct access entities (i.e., sub-national, national or regional organisations from developing countries that could access climate finance directly from the Green Climate Fund). 
- Adequate volume and predictability is another strategic position which is translated through the following demands: increased contributions of the public sector to support the mobilisation of USD 100 billion per year by 2020; enhanced contributions to limit temperature growth under $1.5^{\circ} \mathrm{C}$; increased adaptation finance.

- Transparency and accountability: women organisations demand that climate finance accounting needs to be transparent and available to track climate finance in the long term.

- Additionality: Women organisations appear to have strong positions in relation to the additionality of climate finance to support loss and damage.

In line with the information presented above, there are two inconsistencies in policy framings:

- Inconsistent definition of women organisations: While the UNFCCC's decisions acknowledge three types of women organisations, the references to women organisations in the SCF's policy texts are not aligned with the terms used by the UNFCCC. Womenled organisations are a category of organisations targeted by the SCF. However, this type of organisation may not qualify as an entity with gender equality mandates or have specific knowledge on gender equality issues. As was stated above, grassroots women organisations appear to be one of the important stakeholders of climate finance (as per UNFCCCC decisions). On the other hand, these types of organisations are not recognised in the SCF texts, nor do they appear to represent a significant portion of the WGC membership organisations. As shown in Figure 1, grassroots organisations represent $9 \%$ of constituency members.

- Inconsistent purposes of orchestration: Ambiguous policy mandates, that lack specificity on what the participation is intended to achieve, have been identified as one of the key barriers to orchestration [19]. The orchestration of the participation of women organisations in the UNFCCC generally, and more specifically in climate finance decision-making, appears to be in line with this finding. The UNFCCC's text defines the purpose of mobilising women organisations as improving gender responsiveness of climate finance. The SCF's texts refer to the purpose of improving the gender sensitivity of climate policies through the engagement of women-led organisations. While the terms "gender-responsive" and "gender-sensitive" can be used interchangeably in policy texts, development professionals delineate the terms. Gender-sensitivity is usually referred to the acknowledgment of roles and inequalities. On the other hand, gender responsiveness implies the development of appropriate actions to respond to the existing issues and inequalities [26]. While the WGC aims to increase gender responsiveness of climate finance and climate policies, there are other key policy messages that the women organisations have been conveying through the WGC in relation to climate finance, i.e., equity, additionality, transparency, accountability, accessibility, and predictability which they face similar problems in gaining recognition. Interviewees $C$ and $D$ report that the integration of a gender perspective in climate finance is one of the priorities, however the overarching purpose of mobilisation is to "create better systems for climate and gender justice". Indeed, gender responsiveness is noted as one of the key demands. However, based on experts' feedback, other demands, e.g., transparency, accessibility, predictability, and additionality, are conveyed based on their implicit linkages with gender equality. This being said, there is recognition that linking various demands by WGC members related to gender and climate justice is challenging to capture explicitly within the UNFCCC processes.

\section{Discussion}

The results show that the quality of existing orchestration approaches that support the mobilisation of women organisations has been limited, and so far, the participation of women organisations in the UNFCCC-led climate finance governance has not been associated with any significant impact on policies. However, women organisations are important non-state actors who represent women's interests and have an ability to coordinate and 
synthesise joint positions of women to improve the integration of gender equality issues within climate change policies $[5,6,8]$.

The concept of orchestration is useful for studying the mobilisation of non-state actors within multi-layered governance, however, the orchestration concept has been mostly applied to understand the role of the orchestrator and its abilities to steer participation. While the perspective of an orchestrator is crucial because it shapes the approach to participation, the meta-intermediaries and intermediaries play key roles in the management and organisation of the participation. As the study shows, in complex polycentric governance systems (such as the UNFCCC), meta-intermediaries and intermediaries have their interpretations of the goals of the orchestration. In addition, the targets' capacities may be crucial for ensuring their effective mobilisation.

The quality of orchestration could be affected by the mismatch in the framing of orchestration efforts, which could further lead to sub-optimal orchestration outcomes. Based on the analysis of over 365 documents, this appears to be the case in relation to the orchestration of women organisations' participation in UNFCCC led climate finance decision-making. The study has identified two types of inconsistencies: firstly, in how women organisations (as targets of orchestrations) are defined and, secondly, how the purposes of their mobilisation are seen by the UNFCCC (the Orchestrator), the SCF (the Meta-intermediary) and the WGC (the Intermediary). While integrating a gender perspective in climate finance appears to be a common purpose for mobilising women organisations, the WGC acknowledges other policy demands of women organisations including equity, additionality, transparency, accountability, accessibility, and predictability of climate finance. These findings imply that women organisations' identity and their policy contributions are not well captured.

Aside from discrepancies in framing, there are some process and capacity-related challenges that limit the success of the orchestration efforts. These challenges, to a large extent, are defined by the inherently limited roles of CSOs, including women organisations, within UNFCCC climate finance decision-making processes and a lack of understanding of the utility of their engagement. In addition, the study has found that technical knowledge of women organisations on climate finance issues has been limited. Within the context of the UNFCCC negotiations, which have now become more complex, the lack of understanding of technical issues has been known for disincentivising the engagement of newcomers and actors who are less familiar with technical topics [27]. Thus, capacity building is required to improve access to climate finance training for women organisations.

Within the context of the UNFCCC, the application of top-down engagement models with women organisations (based on initiatives from the top) has been linked with limited participatory outcomes [10]. On the other hand, the "bottom-up" engagement approach, which is based on the creation of adequately funded and accountable national networks of women organisations should lead to better outcomes [10]. However, as the study points out, funding assistance to support the engagement of women organisations in climate finance decision-making has been scarce.

Similar capacity issues have been recognised in other arenas such as holding national governments to account for budgetary allocations [28]. There are tools available, such as gender audits, that can help build the capacity of the orchestration actors to engage more effectively, and in an inclusive manner, in climate finance decision making [29].

Based on the interviewees' feedback, providing evidence to policymakers on the positive contribution of women organisations to climate finance could address these orchestration challenges. However, providing evidence of the positive contributions that women organisations can make is also a challenge since the instrumental narratives around the participation of women organisations are difficult to substantiate. First of all, the ambiguity of framing in relation to women organisations hampers the development of adequate participation indicators (e.g., policy outcomes), which could demonstrate and assess the instrumental value of women organisations' participation. Secondly, even if the policy outcomes are defined, proving the attribution of women organisations to the 
delivery of these outcomes would require the consideration of counterfactual scenarios, i.e., what could happen without the engagement of women organisations. The development of such scenarios within UNFCCC-led orchestration efforts on climate finance may not be attainable.

\section{Conclusions}

The study answered two questions: (1) what are the existing orchestration approaches to support the engagement of women organisations in UNFCCC-led climate finance decision-making and (2) what is the quality of orchestration efforts?

With regard to the first question, the study identified some orchestration approaches. However these approaches are recognised, the actual opportunities to participate are limited. For example:

- The WGC's convening of policy messages is organised mostly through informal bilateral meetings. However, the capacities of the WGC to deliver systemic contributions on behalf of women organisations to climate finance decision-making are noted as limited due to a lack of technical expertise on climate finance issues.

- While agenda-setting opportunities exist and invitations to submit inputs are provided by the SCF's co-chairs, these opportunities are extremely limited since the agendas are guided by the COP decisions and cannot be adjusted even by SCF members.

- Some forms of financial assistance for participation exist but are limited as donors see little value in prioritising the WGC's participation in the SCF's deliberations.

- Endorsement takes place through a number of initiatives, e.g., UNFCCC's Momentum for Change and Gender Just Climate Solutions Awards, which acknowledge the key role of women organisations in addressing broader climate change.

With regard to the second question, the study shows that the quality of orchestration of women organisations in UNFCCC-led climate finance governance has been low. There is a number of challenges within the orchestration process that, if remain unaddressed, are likely to result in only a symbolic mobilisation of women organisations. In line with the triangulation of document analysis and experts' feedback, the following key issues were identified that limit the quality of orchestration:

- Lack of policy convergence between the purposes of orchestration, including limited correlation between how women organisations are defined as targets of orchestration, and what the participation of women organisations is intended to achieve.

- Newness and complexity of the issues on the intersection of climate finance and gender.

- Lack of the WGC's capacity, including technical knowledge of climate finance issues, and consistent prioritisation of climate finance issues in its mandates to aim for and deliver systemic contributions to climate finance decision-making.

One of the key findings of my study is that orchestration at the intersection of climate finance and gender equality is very limited and is associated with a number of orchestration challenges stemming from the newness of this orchestration practice. While orchestration as a concept has been useful for studying the mobilisation of non-state actors within one issue (or focal) area, there is a need for expanding orchestration concepts with knowledge about the intersection of two focal areas, such as climate finance and gender equality.

The study shows that the existing UNFCCC's orchestration approaches are inherently limited. The findings allude that the orchestration of women organisations in the UNFCCCled climate finance governance may be used for symbolic purposes without having a significant impact on policies. To make the engagement with women organisations more meaningful, the following measures could be considered by policy makers:

- Exploring possibilities for experimenting and diversifying the existing orchestration practices, including those related to funding assistance. Generally, the willingness to innovate and entrepreneurial efforts of orchestrators are considered as one of the factors defining the success of orchestration (Abbott et al. 2015). 
- Improving policy framing and reducing the divergence of the purposes of orchestration and roles of meta-intermediaries, intermediaries, and targets. Yet, again the convergence of goals and their correlation is linked with the better success of orchestration (Abbott et al. 2015).

Funding: This research received no external funding.

Data Availability Statement: The data presented in this study are openly available in https:// womengenderclimate.org (accessed on 30 March 2021) and https:/ / unfccc.int/scf/scf-meetings-anddocuments (accessed on 30 March 2021). The data from interviews are not publicly available due to confidentiality reasons.

Acknowledgments: The author thanks Joy S. Clancy and Frans H.J.M. Coenen for their valuable guidance and insights for the completion of this study.

Conflicts of Interest: The author declares no conflict of interest.

\section{References}

1. Nasiritousi, N.; Linnér, B.-O. Open or closed meetings? Explaining nonstate actor involvement in the international climate change negotiations. Int. Environ. Agreem. Politics Law Econ. 2014, 16, 127-144. [CrossRef]

2. Kuyper, J.W.; Linnér, B.; Schroeder, H. Non-state actors in hybrid global climate governance: Justice, legitimacy, and effectiveness in a post-Paris era. Wiley Interdiscip. Rev. Clim. Chang. 2018, 9, 1-18. [CrossRef]

3. Manara, K. The Instrumental Versus the Symbolic: Investigating Members' Participation in Civil Society Networks in Tanzania; Research on Poverty Alleviation: Dar Es Salaam, Tanzania, 2012.

4. Abbott, K.W.; Genschel, P.; Snidal, D.; Zangl, A. Orchestrating Global Governance. In International Organizations as Orchestrators; Cambridge University Press (CUP): Cambridge, UK, 2015; pp. 349-379. [CrossRef]

5. True, J. Mainstreaming Gender in Global Public Policy. Int. Fem. J. Politics 2003, 5, 368-396. [CrossRef]

6. Annesley, C.; Gains, F.; Gains, C.; Annesley, F. The Core Executive: Gender, Power and Change. Political Stud. 2010, 58, 909-929. [CrossRef]

7. McBride, D.E.; Mazur, A.G. Women's Policy Agencies and State Feminism. In Oxford Handbook on Gender and Politics; Waylen, G., Celis, K., Kantola, J., Weldon, L., Eds.; Oxford University Press: Oxford, UK, 2013.

8. Larson, M.J. Transforming power relationships: Building capacity for ecological security. Gend. Dev. 2002, 10, 92-101. [CrossRef]

9. True, J.; Mintrom, M. Transnational Networks and Policy Diffusion: The Case of Gender Mainstreaming. Int. Stud. Q. 2001, 45, 27-57. [CrossRef]

10. Sharma, A. The Reformed Financial Mechanism of the UNFCCC: Renegotiating the Role of Civil Society in the Governance of Climate Finance. 2010. Available online: http:/ / www.oxfordenergy.org/pdfs/EV50.pdf (accessed on 1 April 2021).

11. Hale, T.; Roger, C. Orchestration and transnational climate governance. Rev. Int. Organ. 2013, 9, 59-82. [CrossRef]

12. Bäckstrand, K.; Kuyper, J.W. The democratic legitimacy of orchestration: The UNFCCC, non-state actors, and transnational climate governance. Environ. Politics 2017, 26, 764-788. [CrossRef]

13. Abbott, K.W.; Genschel, P.; Snidal, D.; Zangl, B. Orchestration: Global Governance through Intermediaries. In International Organizations as Orchestrators; Cambridge University Press (CUP): Cambridge, UK, 2015; pp. 3-36. [CrossRef]

14. UNFCCC. Decision 3/CP.25 Enhanced Lima Work Programme on Gender and Its Gender Action Plan; UNFCCC: Bonn, Germany, 2020.

15. Chan, S.; Amling, W. Does orchestration in the Global Climate Action Agenda effectively prioritize and mobilize transnational climate adaptation action? Int. Environ. Agreem. Politics Law Econ. 2019, 19, 429-446. [CrossRef]

16. Thew, H.; Middlemiss, L.; Paavola, J. Does youth participation increase the democratic legitimacy of UNFCCC-orchestrated global climate change governance? Environ. Politics 2021, 30, 1-22. [CrossRef]

17. Bendlin, L. Orchestrating Local Climate Policy in the European Union; Springer: Berlin/Heidelberg, Germany, 2020.

18. Biermann, F.; Kim, R.E. Architectures of Earth System Governance; Cambridge University Press (CUP): Cambridge, UK, 2020; pp. $1-34$.

19. Moynihan, D.P. Normative and Instrumental Perspectives on Public Participation. Am. Rev. Public Adm. 2003, 33, 164-188. [CrossRef]

20. Belfer, E.; Ford, J; Maillet, M.; Araos, M.; Flynn, M. Pursuing an Indigenous Platform: Exploring Opportunities and Constraints for Indigenous Participation in the UNFCCC. Glob. Environ. Politics 2019, 19, 12-33. [CrossRef]

21. Sweetman, C. Gender, Development, and Climate Change. Gend. Dev. Clim. Chang. 2002, 10-112. [CrossRef]

22. Derman, B.B. Climate governance, justice, and transnational civil society. Clim. Policy 2013, 14, 23-41. [CrossRef]

23. UNFCCC. Background Document on the 2019 Workplan of the Standing Committee on Finance. Mandated Activities of the Standing Committee on Finance; UNFCCC: Bonn, Germany, 2019.

24. GCF. Seventh Report of the Green Climate Fund to the Conference of the Parties to the United Nations Framework Convention on Climate Change; GCF: Songdo, Korea, 2018. Available online: https://unfccc.int/sites/default/files/resource/ SeventhReportoftheGCFtoUNFCCCCOP_UNFCCCsubmission.pdf (accessed on 1 April 2021). 
25. UNFCCC. Compendium of Past Guidance Provided to the Green Climate Fund COP 16 to COP 20; UNFCCC: Bonn, Germany, N.d. Available online: https://unfccc.int/files/cooperation_and_support/financial_mechanism/standing_committee/application/ pdf/compendium_gcf.pdf (accessed on 1 April 2021).

26. WHO. Integrating Gender into HIV/AIDS Programmes in the Health Sector: Tool to Improve Responsiveness to Women's Needs; WHO: Geneva, Switzerland, 2009. Available online: https://apps.who.int/iris/bitstream/handle/10665/43980/9789241597197_eng.pdf (accessed on 1 April 2021).

27. Villagrasa, D. Kyoto Protocol Negotiations: Reflections on the Role of Women. Gend. Dev. 2002, 10, 40-44. [CrossRef]

28. Balmori, H.H. Gender and Budgets-Overview Report. BRIDGE (Development-Gender). 2003. Available online: http: //people.umass.edu/econ797f/SyllabusandReadings/Readings/Gender/bridge.gendersensbud.pdf (accessed on 1 April 2021)

29. Clancy, J.S.; Mohlakoana, N. Gender audits: An approach to engendering energy policy in Nepal, Kenya and Senegal. Energy Res. Soc. Sci. 2020, 62, 101378. [CrossRef] 